\title{
Balkanologie
}

Balkanologie Revue d'études pluridisciplinaires

Vol. IV, $n^{\circ} 1 \mid 2000$

Volume IV Numéro 1

\section{Kadaré (Ismail), Il a fallu ce deuil pour se retrouver : journal de la guerre du Kosovo, \\ Paris : Fayard, 2000, 243 p.}

Yves Tomić

\section{CpenEdition}

\section{Journals}

Édition électronique

URL : http://journals.openedition.org/balkanologie/2202

DOI : $10.4000 /$ balkanologie.2202

ISSN : 1965-0582

\section{Éditeur}

Association française d'études sur les Balkans (Afebalk)

Édition imprimée

Date de publication : 1 septembre 2000

ISSN : 1279-7952

\section{Référence électronique}

Yves Tomić, « Kadaré (Ismail), II a fallu ce deuil pour se retrouver : journal de la guerre du Kosovo, », Balkanologie [En ligne], Vol. IV, $n^{\circ} 1$ | 2000, mis en ligne le 29 juillet 2010, consulté le 17 décembre 2020. URL : http://journals.openedition.org/balkanologie/2202 ; DOI : https://doi.org/10.4000/ balkanologie. 2202

Ce document a été généré automatiquement le 17 décembre 2020.

(c) Tous droits réservés 


\section{Kadaré (Ismail), Il a fallu ce deuil pour se retrouver : journal de la guerre du Kosovo,}

Paris : Fayard, 2000, 243 p.

\section{Yves Tomić}

\section{RÉFÉRENCE}

Kadaré (Ismail), Il a fallu ce deuil pour se retrouver : journal de la guerre du Kosovo, Paris : Fayard, 2000, 243 p.

1 Il ne sera pas question ici d'une simple recension de circonstance. En effet, l'ouvrage que nous présentons n'est ni une étude sérieuse, ni le fruit d'une recherche historique quelconque, mais il constitue un matériau ou un objet pour le chercheur s'intéressant au débat intellectuel lié à la guerre du Kosovo et surtout au discours nationaliste albanais contemporain.

2 Les débats sur la guerre du Kosovo sont loin d'être clos. Toutefois, il devient difficile d'avoir un regard critique sur les événements de 1999 dans la mesure où les “détenteurs de la vérité" sur la guerre et l'histoire du Kosovo excluent toute possibilité de discussion ou d'examen critique en qualifiant les auteurs qui exprimeraient des doutes ou des interrogations sur les événements dramatiques de "révisionnistes". Cette disqualification tend à exclure les auteurs critiques ou les chercheurs sérieux du champ du débat. En France, le débat concerne principalement l'action de l'OTAN, le rôle des États-Unis, l'action des médias et beaucoup moins la réalité interne des pays balkaniques. Il est vrai qu'en critiquant le rôle de l'information et des médias, notamment en ce qui concerne le nombre de victimes (Le Monde diplomatique, etc.) certains journalistes ont largement minoré, sinon ignoré, le "nettoyage ethnique" de plusieurs centaines de milliers d'Albanais, ordonné par les autorités serbes. Certes, aujourd'hui, on constate que l'ampleur du drame est moindre : il n'y a pas 100000 
victimes, mais selon toute probabilité 10000 environ. Mais, ce sont 10000 morts de trop. La dénonciation de la désinformation et de la manipulation médiatique de l'OTAN n'a un sens que si ce discours s'inscrit dans une dimension plus large prenant en compte également la nature autoritaire du régime de Slobodan Milošević.

3 Mais revenons à Ismail Kadaré. L'écrivain albanais, véritable ambassadeur de la culture albanaise dans le monde, a largement été sollicité pendant le conflit: il a accordé de nombreux entretiens aux médias, a été invité à divers colloques et conférences, a été reçu au Quai d'Orsay et à l'Elysée. Le quotidien Le Monde lui a ouvert généreusement ses pages en publiant ses tribunes beaucoup plus longues qu'à l'habitude (reproduites dans l'ouvrage). Pourtant, Kadaré est-il un observateur neutre et ses propos contribuent-ils à nous éclairer sur les événements tragiques qui se sont déroulés au Kosovo en 1998-1999 ? En effet, Ismail Kadaré n'est pas uniquement l'écrivain talentueux que l'on connaît, il est également, comme le révèle son journal de guerre, un intellectuel engagé dans la défense de la cause nationale de son peuple. Ses écrits divers (non-littéraires) nous montrent également qu'il est un idéologue de la nation albanaise. Ismail Kadaré ne cache pas sa sympathie pour l'Armée de libération du Kosovo (UCK, projetée « vers l'avenir : vers la civilisation européenne ») et son aversion pour les "ultrapacifistes albanais" regroupés autour d'Ibrahim Rugova. Il règle également ses comptes avec Adem Demaqi qui fut un temps le représentant politique de l'UCK et qui s'opposa aux négociations de Rambouillet :

Le comportement fantasque de cet homme est scandaleux. On lui a pardonné jusqu'ici bien des erreurs et des fautes, mais voilà que ça dépasse tout ce qui est permis! Il ne s'agit plus désormais de bévue, mais de crime! Le Kosovo paie chaque foucade de ce personnage du sang et du supplice, de la mort de ses enfants (p. 30).

Ismail Kadaré dénonce également les "renégats albanais", en fait des intellectuels (Fatos Lubonja, Veton Surroi, etc.) demeurés critiques face au nationalisme albanais et ne partageant pas ses positions (pp. 101-102). Ses critiques, ses accusations devrionsnous dire, visent en fait tous ceux n'adhérant pas à sa version de l'histoire albanaise. $C^{\prime}$ est ainsi que le jeune historien, Bruno Cabanes, auteur avec son père, Pierre Cabanes, d'un ouvrage sur l'Albanie ${ }^{1}$ est accusé de "perfidie" :

Or, voici qu'au beau milieu de la tragédie du Kosovo, ce connaisseur des réalités albanaises, chercheur en ce domaine, loin de prononcer le moindre mot pour défendre les Albanais, évoque brusquement avec flamme la violence de leur caractère, les mythes qu'ils auraient selon lui créés à propos de Skanderbeg ou sur leurs origines illyriennes, etc. Autrement dit, en un temps où la moitié du peuple albanais tombe sous la hache du bourreau, cet homme nommé Bruno Cabanes vient plonger son couteau dans le dos de l'autre moitié.

Les données du problème sont simples : tout historien exposant une version raisonnée de l'histoire albanaise contredisant la version romantique et mythique défendue par Ismail Kadaré est un "criminel”! Toutes les invectives contenues dans l'ouvrage nous révèle un Kadaré peu soucieux du pluralisme des idées. Ismail Kadaré n'a pas été élevé à l'école de la démocratie. Les pages de son journal regorgent de son intolérance et l'on voudrait nous faire croire qu'il est un observateur éclairé et démocrate des réalités balkaniques!

Ismail Kadaré développe une vision largement ethnocentriste de l'histoire des Balkans. Les Albanais sont meilleurs que les autres peuples de la péninsule; ils sont les plus hospitaliers des Balkans; l'Albanie se situe au premier rang dans le monde en ce qui concerne la tolérance religieuse, l'Albanie est le pays le plus démocratique des Balkans, 
etc. À l'inverse, les Serbes n'appartiennent pas au monde civilisé : ils s'adonnent à la "barbarie", la "sauvagerie", au "cannibalisme"; ils "ont une soif bestiale de sang"; ils possèdent une "mentalité barbare". Les Serbes, criminalisés et bestialisés, sont ainsi considérés comme un ensemble homogène partageant tous les mêmes valeurs, aspirations et sentiments. Ils se retrouvent ainsi déshumanisés, animalisés. De surcroît, ces vices sont permanents : « les grands crimes sont habituellement la répétition des crimes anciens qui se manifeste de manière cyclique». Ainsi, Ismail Kadaré date l'origine de l'ethnocide à la période de l'arrivée des Slaves dans la péninsule balkanique! Le "rêve serbe" du "nettoyage ethnique" des Albanais du Kosovo est vieux de mille ans! L'auteur albanais explique la violence des Serbes par leur revanchisme: sous l'Empire ottoman, les Albanais figuraient «parmi les nations les plus favorisées, les Serbes parmi les plus opprimées et les plus méprisées ", d'où la jalousie exprimée par les Serbes à l'encontre des Albanais. Cette présentation est très simplificatrice. En réalité, l'Empire ottoman ne reconnaissait pas les nations, mais était structuré sur la base des confessions et des communautés religieuses. Les Serbes n'ont pas été particulièrement plus opprimés que les autres chrétiens des Balkans : ils ont même pu se détacher du patriarcat œcuménique de Constantinople et bénéficier d'une autonomie confessionnelle de 1557 à 1767.

7 À bien des égards, Ismail Kadaré développe une grille de lecture racisante de l'histoire balkanique. En effet, selon lui, il existe deux catégories de peuples dans la péninsule balkanique : les "autochtones" et les "envahisseurs" (les Slaves principalement). Les Albanais et les Grecs sont les deux peuples les plus anciens de la péninsule balkanique, tandis que les Slaves du sud arrivés pourtant aux VI ${ }^{\text {ème }}$ et VII ${ }^{\text {ème }}$ siècles sont toujours perçus comme des "envahisseurs" ou de "banals occupants". Le romancier albanais est obsédé par la question des origines du peuple albanais et du premier occupant, le seul à pouvoir revendiquer le droit de propriété sur les territoires qu'il habite. Ce qui importe, c'est que les Albanais habitaient le Kosovo mille ans avant l'arrivée des Slaves. En conséquence, la présence serbe au Kosovo relève de l'imposture, de la falsification de l'Histoire, du "conte pour enfants" ou encore de la "fable". L'approche est clairement différentialiste: selon lui, les Albanais du Kosovo, orthodoxes, se sont convertis à l'islam pour se distinguer des Serbes également de confession orthodoxe. Mais alors pourquoi les Albanais du territoire de l'actuelle Albanie, qui n'étaient pas en contact avec les Serbes, ont-ils adopté la religion musulmane? Cette thèse plus que bancale ignore complètement les travaux des historiens ottomanisans qui ont traité de cette problématique. Ses positions sont également fondées sur un relativisme culturel très prononcé : « les Serbes et la Serbie n'ont jamais capté l'attention des Albanais. Dans la tradition culturelle, on les retrouve évoqués quasiment nulle part, si ce n'est simplement comme l'“ennemi" dans certains clichés et surtout dans les chants épiques du nord».

8 Évoquant le chef du Mouvement serbe du renouveau (SPO), Vuk Drašković, Ismail Kadaré se réfère à des phénotypes: «Draskovic, par sa physionomie, évoque la brutalité balkanique ». Il y avait bien d'autres registres ou manières de dénoncer la violence perpétrée contre les Albanais du Kosovo par le régime autoritaire de Slobodan Milošević et son appareil répressif. Ismail Kadaré dénonce le racisme des Serbes. La xénophobie existe réellement dans la société serbe, mais elle est loin d'être partagée par l'ensemble de ses membres. Le plus affligeant est qu'il le fait en utilisant des éléments ou des catégories de la "pensée raciste" : essentialisation et barbarisation. 


\section{NOTES}

1. Cabanes (Bruno), Cabanes (Pierre), Passions albanaises: de Berisha au Kosovo, Paris: Odile Jacob, 1999.

\section{AUTEURS}

YVES TOMIĆ 